\title{
High predictability of spring phytoplankton biomass in mesocosms at the species, functional group and community level
}

\author{
BARBARA BAUER*, ${ }^{\star}$, ULRICH SOMMER ${ }^{\dagger}$ AND URSULA GAEDKE* \\ *Institute for Biochemistry and Biology, University of Potsdam, Potsdam, Germany \\ ${ }^{\dagger}$ Helmholtz Centre for Ocean Research Kiel (GEOMAR), Kiel, Germany
}

\section{SUMMARY}

1. Models aim to predict phytoplankton dynamics based on observed initial conditions and a set of equations and parameters. However, our knowledge about initial conditions in nature is never perfect. Thus, if phytoplankton dynamics are sensitive to small variations in initial conditions, they are difficult to predict.

2. We used time-series data from indoor mesocosm experiments with natural phyto- and zooplankton communities to quantify the extent to which small initial differences in the species, functional group and community biomass in parallel treatments were amplified or buffered over time. We compared the differences in dynamics between replicates and among all mesocosms of 1 year.

3. Temperature-sensitive grazing during the exponential growth phase of phytoplankton caused divergence. In contrast, negative density dependence caused convergence.

4. Mean differences in biomass between replicates were similar for all hierarchical levels. This indicates that differences in their initial conditions were amplified to the same extent. Even though large differences in biomass occasionally occurred between replicates for a short time, dynamics returned to the same path at all hierarchical levels. This suggests that internal feedback mechanisms make the spring development of phytoplankton highly predictable.

Keywords: divergence, hierarchical level, mesocosms, predictability, replicates

\section{Introduction}

Phytoplankton constitutes almost $50 \%$ of global primary production and is the base of the pelagic food web. Thus, forecasting the yearly development of phytoplankton communities in the future is of high importance. Ecologists have used a number of models to represent and predict phytoplankton community dynamics. A model prediction is defined as the evaluation of the future state of a system based on a set of initial conditions, forcing and the mathematical representation of relevant ecological processes. Based on model predictions, using the best available data, ecologists are able to give forecasts, that is, probabilistic statements of the future state of a system (Luo et al., 2011). To assess the reliability of model predictions for the purpose of forecasting, we need not only to estimate our uncertainty about initial conditions, forcing and other factors influencing dynamics but also to assess the sensitivity of the dynamics to each of these factors. Species composition is harder to monitor than abiotic forcing; thus, if the community biomass of systems with a similar initial species composition and under the same forcing shows different dynamics (i.e. diverge from each other over time), they are unpredictable, that is, the uncertainty of the predictions made about them is large.

Historical effects (e.g. microevolution, founder effect) or previous differences in environmental forcing cause natural variability in total biomass and species composition among similar phytoplankton communities. Divergence or convergence of the total biomass among these

Correspondence: Barbara Bauer, Helmholtz Centre for Ocean Research Kiel (GEOMAR), Düsternbrooker Weg 20, D-24105 Kiel, Germany.

E-mail: bauerb@uni-potsdam.de

(c) 2012 Blackwell Publishing Ltd

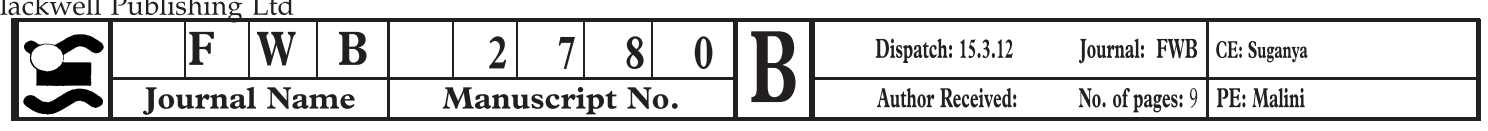




\section{B. Bauer et al.}

communities depends on the relevance of negative density-dependent feedback processes acting upon it. For example, competition for light or nutrients and densitydependent predation (Morin, 1995) regulate the biomass of the whole phytoplankton community, regardless of its species composition. Thus, if negative density-dependent processes play an important role in community regulation, the biomass development is influenced more by light availability or the presence of a generalist predator than by the exact initial phytoplankton species composition. In this case, the total biomasses of similar communities are expected to converge. Hence, their fate is predictable with models incorporating a few regulatory mechanisms (Tilman, 1990).

Individual species are not only affected by communitylevel regulation but also by species-specific densitydependent regulation such as selective predation and host-specific pathogens. These processes are sensitive to the presence and absence of interacting species, that is, they are highly context-dependent (Holt, 1977). Thus, species dynamics were proposed to be less predictable than community dynamics (Dakos et al., 2009). Individual species and functional groups might differ in their predictability based on the strength of the negative density-dependent feedbacks regulating them. For example, smaller algae, grazed by protozoan predators with short generation times and high growth rates, are less likely to reach high densities than larger algae, grazed by mesozooplankton with complex life cycle and low growth rates.

Clearly, there is no strict line between processes acting on the species vs. the community level. For example, different species react differently to nutrient concentrations owing to their different nutrient requirements. Thus, how much a given nutrient concentration limits the growth rate at the community level depends on the species composition as well as on the biomass of the community.

For a better understanding of the processes driving changes in biomass, ecologists often study the dynamics of process rates. The production-to-biomass $(\mathrm{P} / \mathrm{B})$ ratio characterises phytoplankton turnover. It is an oftenstudied process rate, which is determined mostly by available light levels and total community biomass. Thus, its predictability is probably similar to that of the community biomass.

Assessing predictability at different hierarchical levels within the phytoplankton community is crucial for directed data collection, model selection and setting realistic expectations towards the predictive power of science. Comparisons of the predictability of hierarchical levels are useful to avoid trying to predict dynamics on the 'wrong' level (Rahel, 1990). In the latter case, our efforts might remain futile or we set overly optimistic expectations about the time needed to develop predictions or management plans.

To gain insight into the mechanisms behind the predictability of phytoplankton spring development, we compared how the biomass of paired experimental phytoplankton communities differed through time. We used phytoplankton biomass data from mesocosm experiments conducted over 5 years with early spring natural communities (Sommer \& Lewandowska, 2011 and literature cited therein). The mesocosms were run in a highly controlled environment with several realistically changing abiotic (temperature, light) and biotic (copepod grazing) forcing factors and included the complex natural grazer community. The mesocosms of 1 year were started with similar initial densities and composition of phytoand zooplankton and were partly subject to different treatments; 28 pairs of mesocosms, the experimental replicates, were run under the same environmental forcing.

We tested the degree of difference in biomass among the replicates and treatments depending on the hierarchical level (species, functional groups, entire community) and its change over time (i.e. the level of divergence) during planktonic succession. Additionally, we conducted the same analyses on the time series of the $\mathrm{P} / \mathrm{B}$ ratio of the community. We hypothesised that (i) the dynamics of total phytoplankton biomass differed more among all mesocosms within 1 year than between replicates as environmental forcing strongly influences phytoplankton dynamics; (ii) divergence and difference at the community level is lower than at the functional group and species level; (iii) at high levels, total phytoplankton biomasses of replicates converge because of strong density dependence; and (iv) divergence and difference of the $\mathrm{P} / \mathrm{B}$ ratio is similar to that of community biomass.

\section{Methods}

\section{The Kiel mesocosms}

The data used in this analysis were obtained from mesocosm (1400 L, $1 \mathrm{~m}$ depth) experiments conducted over 5 years with early spring phyto- and zooplankton communities from the Kiel Fjord, Western Baltic Sea, Germany. The mesocosms were filled simultaneously with unfiltered water from the fjord, which contained overwintering populations of phytoplankton, bacteria, protozoans and mesozooplankton larvae. Larger 
mesozooplankton (mainly copepods) obtained from net catches from the fjord were added at natural abundance (2005-2008 experiments) or in three different abundances (2009 experiment). From February to May 2005, 2006 (two experiments) and 2007 eight indoor mesocosms were run under four different temperature regimes (four pairs of replicates for each year). In 2008 and 2009, twelve mesocosms (six pairs of replicates) were run under two temperature regimes and three light regimes (2008) or started with three different copepod densities (2009) (Table 1). The mesocosms were gently mixed by a propeller to assure a homogeneous distribution of the plankton. Temperatures followed the observed seasonal course of the Kiel Bight, the coldest ('baseline') corresponding to the decadal average 1993-2002 and the three others with $+2,+4$ and $+6{ }^{\circ} \mathrm{C}$ temperature elevation above the baseline from the beginning until the end of February. After that, the temperature difference between the treatments was reduced by $0.25{ }^{\circ} \mathrm{C}$ per month to mimic the less pronounced warming later in the year. The daylength was adjusted to natural conditions. The light regime followed the natural solar irradiance $\left(\mathrm{I}_{0}\right)$, which was calculated from astronomic models for each day

1 (Brock, 1981) and reduced in the range of $16-100 \%$ in the various experiments (for details about the experimental set-up see Sommer et al., 2007; Sommer \& Lengfellner, 2008; Lewandowska \& Sommer, 2010; Sommer \& Lewandowska, 2011). Irradiance increased 11-fold during the experiments.

Phytoplankton were sampled three times per week from mid-depth $(0.5 \mathrm{~m})$ of the well-mixed mesocosms.

Table 1 Overview of the experimental treatments. 1-factor experiments included four levels of temperature and 2-factor experiments included two levels of temperature and three levels of light intensity or initial copepod densities

\begin{tabular}{|c|c|c|c|}
\hline \multicolumn{4}{|c|}{ 1- Factor experiments } \\
\hline Year & $\begin{array}{l}\text { Duration } \\
\text { (days) }\end{array}$ & Temperature & $\begin{array}{l}\text { Light } \\
\text { intensity } \\
(\%)\end{array}$ \\
\hline \multicolumn{4}{|c|}{ 2005-2007 } \\
\hline 2005 & 91 & $\Delta \mathrm{T}=+6 ;+4 ;+2 ;+0{ }^{\circ} \mathrm{C}$ & $\mathrm{I}_{0}=16$ \\
\hline 2006-1 & 38 & $\Delta \mathrm{T}=+6 ;+4 ;+2 ;+0{ }^{\circ} \mathrm{C}$ & $\mathrm{I}_{0}=100$ \\
\hline $2006-2$ & 68 & $\Delta \mathrm{T}=+6 ;+4 ;+2 ;+0{ }^{\circ} \mathrm{C}$ & $\mathrm{I}_{0}=64$ \\
\hline 2007 & 81 & $\Delta \mathrm{T}=+6 ;+4 ;+2 ;+0{ }^{\circ} \mathrm{C}$ & $\mathrm{I}_{0}=32$ \\
\hline \multicolumn{4}{|c|}{ 2-Factor experiments } \\
\hline \multicolumn{4}{|c|}{$2008-2009$} \\
\hline 2008 & 49 & $\Delta \mathrm{T}=+6 ;+0{ }^{\circ} \mathrm{C}$ & $\begin{array}{l}\mathrm{I}_{0}=49 ; 57 ; 62 \% \\
\text { Initial density of } \\
\text { copepods }(\mathrm{ind} / \mathrm{L})\end{array}$ \\
\hline 2009 & 38 & $\Delta \mathrm{T}=+6 ;+0{ }^{\circ} \mathrm{C}$ & Cops $=1.5 ; 4 ; 10$ \\
\hline
\end{tabular}

Phytoplankton $>5 \mu \mathrm{m}$ were counted by inverted microscopy and distinguished at the genus level in most cases. Small phytoplankton were counted by a flow cytometer (FACScalibur, Becton Dickinson) and distinguished by size and fluorescence of chlorophyll a and phycoerythrin. Phytoplankton biomass was estimated as carbon calculated from cell volumes (Menden-Deuer \& Lessard, 2000), which was derived from linear measurements after approximation to the nearest geometric standard solid (for details about the calculation of phytoplankton biomass, see Sommer \& Lewandowska, 2011 and literature cited therein). Primary production data were available to us between 2007 (18 data points altogether, with more frequent data during the first half of the experiment) and 2008-2009 (sampled every second working day) and was calculated from ${ }^{14} \mathrm{C}$-bicarbonate uptake using samples incubated inside the mesocosms at medium depth (data for 2007: Breithaupt, 2009; data for 2008-2009: Lewandowska, 2011).

\section{Data analysis}

Based on the feeding preferences of the dominant grazers (large ciliates and copepods), phytoplankton was divided into two functional groups: edible (diatoms and filamentous species $500-1000<\mu \mathrm{m}^{3}$ cell volume, except for several large species, see below) and less edible forms (Sommer \& Sommer, 2006). The latter was subdivided into two groups, less edible small algae (autotrophic picoplankton, nanoplankton $<500-1000 \mu^{3}$ cell volume) and less edible large algae (including the big diatoms Coscinodiscus sp., Rhizosolenia setigera and the dinoflagellates Ceratium fusus and Ceratium tripos).

We studied predictability by quantifying the difference between paired mesocosms and all mesocosms within a year and its change in time at various hierarchical levels. Besides the difference in the biomass of total phytoplankton, we examined the difference in the biomasses of the three functional groups and of the taxonomic-functional group autotrophic picoplankton (flow cytometric types not matched to species, $1-30 \mu \mathrm{m}^{3}$, Sommer \& Lewandowska, 2011) and several phytoplankton species. The latter were chosen because they were present in sufficient abundances for extended periods of time in most of the years and span a large size range: Rhizosolenia alata (cell volume: $\quad 37700 \mu \mathrm{m}^{3}$ ), Thalassionema nitzschioides $\left(1800 \mu \mathrm{m}^{3}\right)$, Chaetoceros curvisetus $\left(1500 \mu^{3}\right)$, Heterocapsa rotundata $\left(430 \mu \mathrm{m}^{3}\right)$ and Skeletonema costatum $\left(283 \mu \mathrm{m}^{3}\right)$. We also conducted the same analysis on the $\mathrm{P} / \mathrm{B}$ ratio. We performed a $\log _{2}$ transformation on biomass and $\mathrm{P} / \mathrm{B}$ data to insure equal weight to all sampling dates regardless of

(C) 2012 Blackwell Publishing Ltd, Freshwater Biology, doi:10.1111/j.1365-2427.2012.02780.x 


\section{B. Bauer et al.}

the absolute values on each date and ignored dates with zero biomass in at least one of the replicates.

We calculated divergence $V_{t}$, that is, the change of the difference with respect to time, according to the following equation:

$$
V_{t}=\left|x_{t, 1}-x_{t, 2}\right|-\left|x_{t-1,1}-x_{t-1,2}\right|
$$

where $x_{t, 1}$ and $x_{t, 2}$ are the $\log _{2}$-transformed values of biomass (of species, functional groups or communities) or $\mathrm{P} / \mathrm{B}$ data in the compared mesocosms on date $t$. Values $<0$ indicate convergence, values $>0$ divergence, and 0 indicates no change in difference. We only calculated the amount of divergence, $V_{t}$, between two successive sampling dates as the index is only informative about dynamics if calculated over short time-frames. For example, if mesocosm 1 has half the value of mesocosm 2 at time 1, but double the value of mesocosms 2 at time 2, this is a very strong change through time, but $V_{t}$ remains zero as the amount of divergence that happened during this time is the same as the amount of convergence.

We quantified the mean difference $(D)$ in the $\log _{2^{-}}$ transformed values with the index:

$$
D=\frac{\frac{1}{n} \cdot \sum_{t=1}^{n}\left|x_{t, 1}-x_{t, 2}\right|}{\frac{1}{3} \cdot \sum_{t=1}^{3}\left|x_{t, 1}-x_{t, 2}\right|}
$$

where $n$ is the number of dates in a given year when phytoplankton samples or production measurements were available or, in the case of species, the number of sampling dates when the given species was found in both samples.

Values of $D$ express the mean factorial difference between the biomasses or $\mathrm{P} / \mathrm{B}$ of two mesocosms divided by their mean initial difference during the first three sampling dates, that is, the first week of the experiment. We took the mean of the first three sampling dates to reflect the fact that some cells counted just after filling are not alive and therefore do not contribute to the dynamics of the community later. The standardisation with the mean initial difference was necessary because the initial differences in species biomasses between the mesocosms were higher than for the functional groups and total community biomass. The index $D$ is independent of the units and the magnitude of the variables because it is based on relative differences. This renders index $D$ suitable to compare hierarchical levels and periods within an experiment and among treatments. $D$ is high if the average difference through time between two mesocosms is much higher than the initial difference, indicating prevalent divergence (Fig. 1a). D is close to 1 when the initial differences are maintained on average (memory effect), but are neither amplified nor buffered (Fig. 1b). D is smaller than 1 when the biomasses in the two mesocosms predominantly converge (Fig. 1c). This way, $D$ expresses our intuitive notion of 'unpredictability': systems where small initial differences are amplified are unpredictable, and systems where they are maintained or buffered are predictable.

After calculating $D$ for all replicates, the mean values were taken for further comparisons for all functional groups and species with the following exceptions: the values for Heterocapsa rotundata, Rhizosolenia alata and Thalassionema nitzschioides in 2005, two pairs of replicates in the case of Chaetoceros curvicetus and Rhizosolenia alata, and all pairs in the case of Thalassionema nitzschioides in 2007. These were excluded from the calculations of $D$ for the species level owing to poor counting statistics resulting from low abundances. The data from 2005 to 2007 for the large less edible functional group were not analysed because of its extremely low abundances in these years.
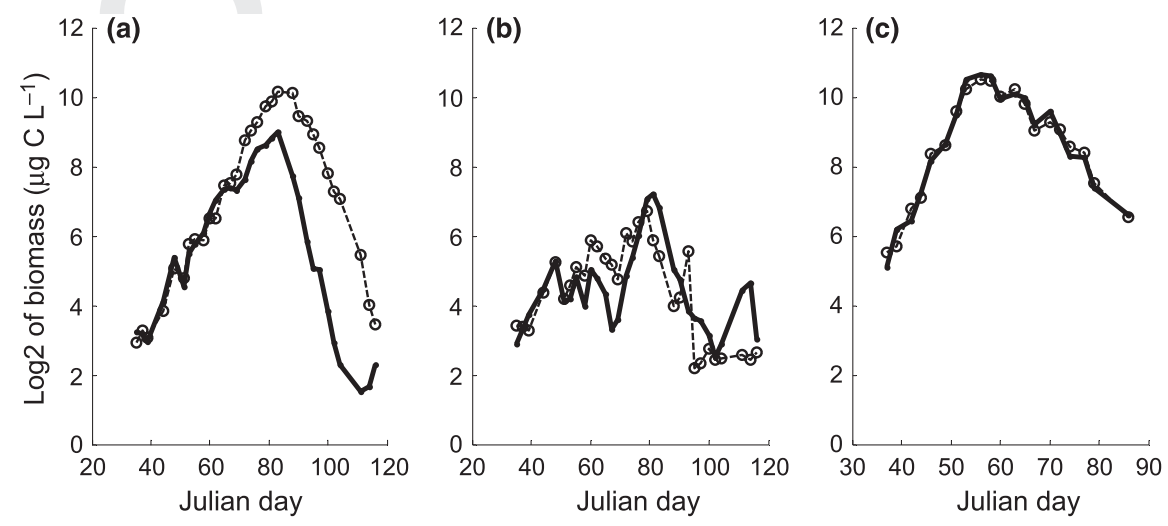

Fig. 1 Examples of pairs of replicates with (a) high $(D=8.35)$, (b) intermediate $(D=2.26)$ and c) low $(D=0.43)$ mean difference, $D$, calculated for the total phytoplankton biomass. 
To test for differences in the mean $D$ between the different functional groups and the P/B ratio, we conducted an ANOvA followed by a post hoc test (Tukey's HSD; Tukey, 1951), using the groups as fixed factors. We performed a similar analysis in the case of the species. We compared the grand mean of the $D$ values of the functional groups and the grand mean of the $D$ values of the species, assessing their difference with a $t$-test assuming unequal variances. Additionally, for each year, we calculated mean $D$ of the total phytoplankton biomass and species and of the $\mathrm{P} / \mathrm{B}$ ratio based on the difference among all mesocosms of the year. We compared the difference between the grand mean of $D$ calculated this way to that calculated based on replicates between the phytoplankton and the species level with a $t$-test assuming unequal variances.

\section{Results}

All mesocosms were similar in the general pattern of phytoplankton succession. In most of the mesocosms, the total phytoplankton biomass initially increased and it decreased after reaching its peak.

\section{Treatments vs. replicates}

The divergence, $V_{t}$ (i.e. the change of the difference), of the total biomass between any two mesocosms within 1 year showed a distinct pattern in time. Initially, it increased markedly but decreased during the second half of the experiments (Fig. 2a). In contrast, $V_{t}$ values of the replicates calculated for the total biomass were variable over the experiments (Fig. 2b), which means that divergent and convergent dynamics occurred throughout the experiments between replicates. Occasionally extreme divergences were observed between two replicates, especially during the second half of the experiments, but we did not find any distinct relationship between their timing and the phase of phytoplankton succession. $V_{t}$ values of the $\mathrm{P} / \mathrm{B}$ between replicates and among treatments were also variable without any distinct temporal pattern.

As expected, the dynamics of biomasses and $\mathrm{P} / \mathrm{B}$ ratios were more similar between replicates than among different treatments. The mean $D$ of all years for total phytoplankton biomass calculated based on the difference between any mesocosm to any other mesocosm in the same year was 3.44 (standard deviation: 1.38), whereas the
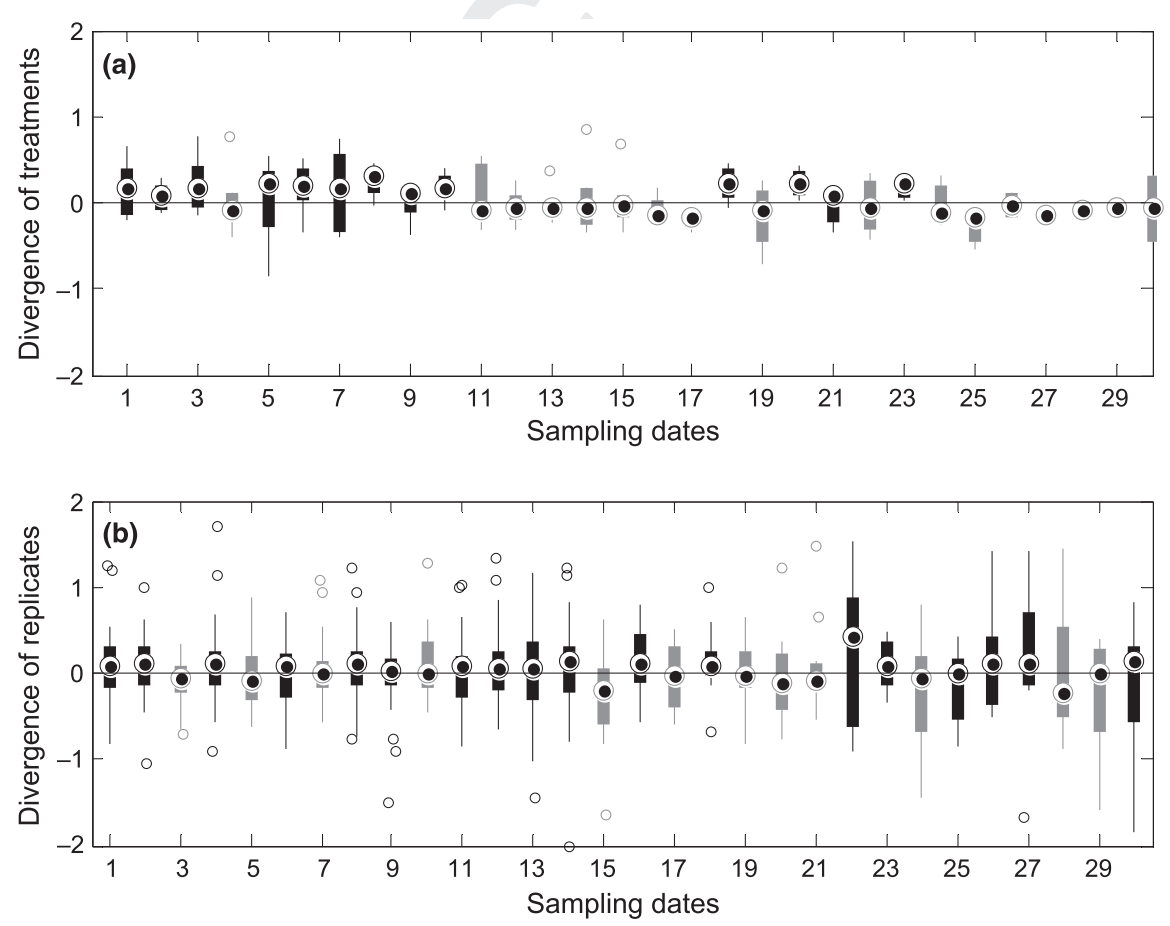

Fig. 2 Divergence, $V_{t}$, for total phytoplankton biomass for the sampling dates indicated on the $x$-axis among mesocosms of 1 year (i.e. partly different treatments) (a) and between replicates (b). As most of the experiments were conducted for $<70$ days (i.e. sampled $<30$ times), data from sampling dates $>30$ are not shown. Black boxes indicate dates when the median of $V_{t}$ values for all pairs of mesocosms was above zero, indicating divergence on the given date compared to the previous date, while grey boxes indicate convergence. The central mark in each box is the median, the edges of the box are the 25th and 75th percentiles, the whiskers extend to the most extreme data points not considering outliers, and outliers are plotted individually. $V_{t}$ calculated for species, functional groups and $\mathrm{P} / \mathrm{B}$ ratios show a pattern similar to b). 


\section{B. Bauer et al.}

mean $D$ for total phytoplankton biomass of replicates was 2.26 (standard deviation: 1.58, Fig. 3a). The D values calculated for species based on the differences of all mesocosms ranged from 1.7 to 2.3 (with standard deviations ranging from 0.8 to 1.8 ), similar to the range based on the replicates (mean values: 1.5-2.2, standard deviations: $0.9-3$, Fig. $3 b$ ). Hence, the difference between $D$ calculated for all mesocosms and for replicates was significantly smaller at the species level than for the total phytoplankton ( $t$-test, $t=2.39$, d.f. $=27, P<0.05$ ). This seems to suggest that the treatments had less effect at the species than at the community level. However, the index $3 D$ is normalised with the initial differences, which were 4 larger for species biomasses than for total phytoplankton biomass. This implies that it was harder to detect an effect of the treatments for the species than for the total phytoplankton biomass.

Mean D of P/B based on replicates was 1.32 (standard deviation: 0.6, Fig. 3a), very close to the value based on the difference of all mesocosms, which was 1.16 (standard deviation: 0.41 ). The second value being slightly smaller than the first is counterintuitive and is a result of normalising $\mathrm{D}$ with the mean difference of the first three sampling dates (eqn 2), which was larger among all mesocosms than between replicates. Nevertheless, without normalisation, the two values still fall in the same range: mean D of replicates was 0.72 (standard deviation: 0.2 ) and mean D of all mesocosms was 0.99 (standard deviation: 0.14).

\section{Divergence $\left(\mathrm{V}_{t}\right)$ and mean difference $(\mathrm{D})$ at various hierarchical levels}

$V_{t}$ values calculated for the species and functional group biomasses were variable over time among all mesocosms and between the replicates (functional groups, between replicates: mean: 0.03, standard deviation: 0.64 , among all mesocosms: mean: 0.07, std: 0.38; species, between replicates: mean: 0.04 , std: 1.07 , among all mesocosms: 0.14 , std: 0.57), similarly to those calculated for the total phytoplankton biomass.

Except for picophytoplankton, $D$ values of all the hierarchical levels studied were around two (median D values range: $1.1-2.72$, Fig. 3 ); that is, on temporal average, the difference between the replicates was twice as much as during the first three sampling dates.

$D$ of the functional-taxonomic group picophytoplankton was significantly higher than $D$ of the total phytoplankton, the functional groups and of the $\mathrm{P} / \mathrm{B}$ ratio (Tukey's HSD, $P<0.05$, Fig. 3a). There were no significant differences among the $D$ values of the species (Fig. 3b, ANOVA, $P>0.6$ ). Similarly, there was no significant difference between the grand mean of $D$ of the functional groups (picophytoplankton excluded) and of the species ( $t$-test, $t=0.64$, d.f. $=54, P>0.5$ ). The mean $D$ value of the $\mathrm{P} / \mathrm{B}$ ratio was not significantly different from that of the biomass of the functional groups or species, but it varied only in a remarkably narrow range (Fig. 3a).
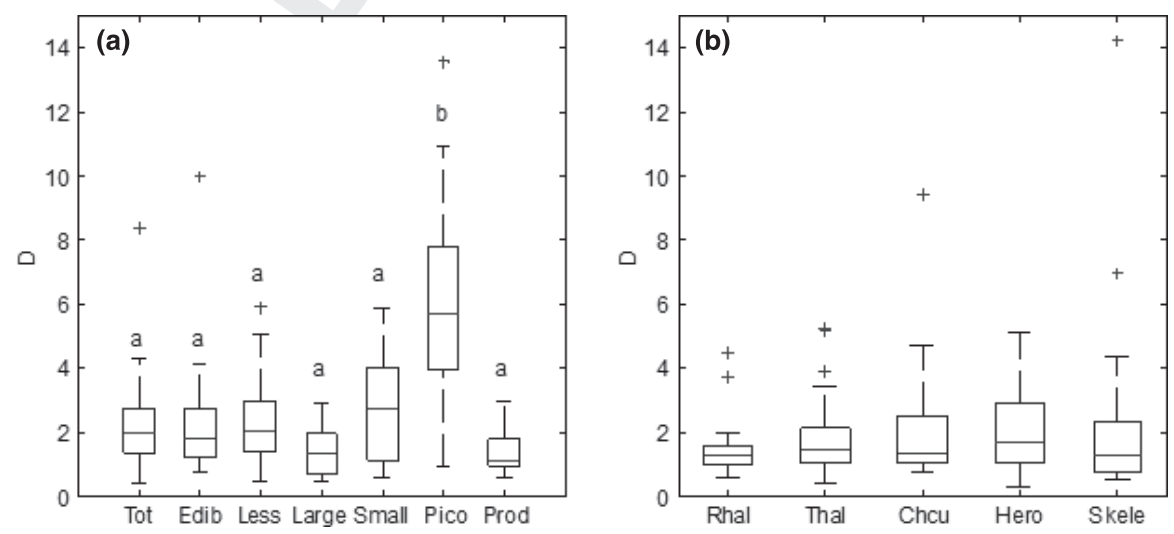

Fig. 3 Difference index, D calculated between replicates 2005-2009 for (a) total phytoplankton biomass and P/B and biomass of functional groups and (b) species biomass. The abbreviations mean: tot $=$ total, edib $=$ edible, totless $=$ total less edible, small $=$ small less edible, large $=$ large less edible phytoplankton, pico $=$ picoplankton, prod $=\mathrm{P} / \mathrm{B}$, and Rhal $=$ Rhizosolenia alata, Thal $=$ Thalassionema nitzschioides, $\mathrm{Chcu}=$ Chaetoceros curvicetus, Hero $=$ Heterocapsa rotundata, Skele $=$ Skeletonema costatum. The letters ' $a$ ' and ' $\mathrm{b}$ ' above the boxes in the left panel indicate two significantly different groups after the Tukey's HSD test $(\alpha<0.05)$. There were no significant differences in $D$ among species $(b)$. The central mark on each box is the median, the edges of the box are the 25th and 75th percentiles and the whiskers extend to the most extreme data points not considering outliers. The crosses indicate outliers. For the sake of better visualisation, one outlier was omitted: a $D$ value of 24.3 for picophytoplankton. 


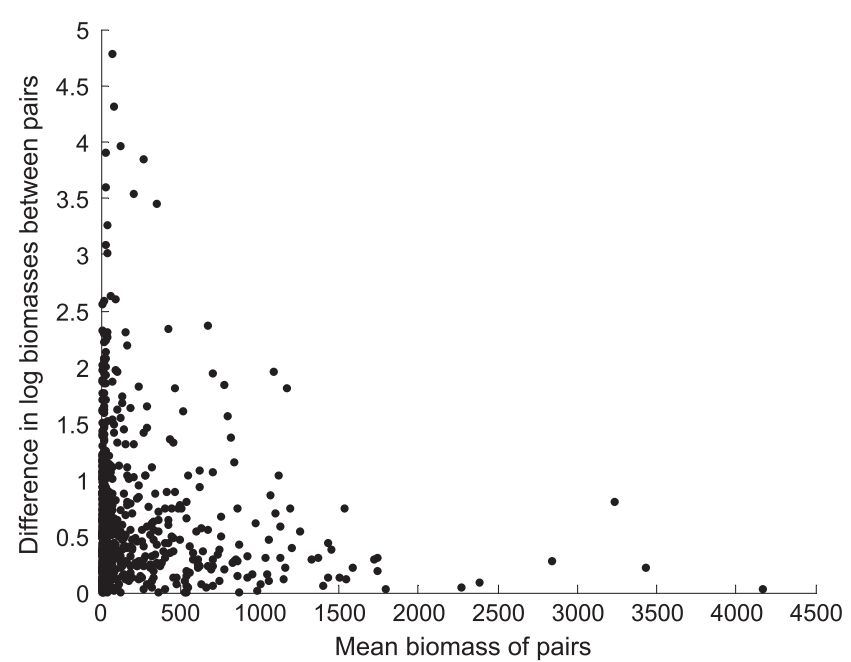

Fig. 4 The relationship between the absolute difference in the $\log _{2}-$ transformed biomasses of the mesocosm pairs $\left|x_{1}-x_{2}\right|$ and the mean total phytoplankton biomass of the mesocosm pairs on individual sampling dates. At high mean algal biomasses, differences between the two replicates were small, even in absolute values. At low mean biomasses, the replicates could be either similar or different.

\section{A mechanism of convergence: negative density dependence as a regulating factor}

Comparing the difference in the log-transformed total phytoplankton biomasses of the two replicates on a given date with their mean total phytoplankton biomass shows that differences between replicates were very low $(<1)$ during periods with high biomass (1500-4500 $\mu \mathrm{g} \mathrm{C} \mathrm{L}^{-1}$, Fig. 4). In contrast, during periods with lower biomasses, the difference values between the two replicates ranged from very small to a factor of 5 (Fig. 4). On dates with high biomass values, the maximum measured $\mathrm{P} / \mathrm{B}$ ratios reached 0.04-0.54, which is a lower range than the maximum value during periods with lower biomasses, 2.04. This indicates bottom-up limitation when the biomass values were high.

\section{Discussion}

We analysed divergence $(V)$ and difference $(D)$, as indicators for predictability, of phytoplankton biomass and production between mesocosms to answer the question: How constrained and predictable do natural phytoplankton behave when influenced by complex food web interactions and realistic abiotic forcing?

Overall, even the most different treatments were similar in their general pattern, an increase in total biomass, driven by increasing light levels, and a decrease in biomass under nutrient depletion and severe grazing pressure by herbivores, as also observed in field studies of spring phytoplankton (Sommer et al., 1986). Nutrient depletion and grazing caused negative density dependence at the community level, which led to convergence in total biomass between replicates. In agreement with our first hypothesis, we observed a trend that the treatments within 1 year differed from each other more than the replicates in the case of the total phytoplankton. This was mostly due to strong divergences among the treatments in the exponential growth phase (Fig. 2a). During this period, phytoplankton dynamics were sensitive to light levels and grazing intensity, which depended on temperature in addition to grazer biomasses. Available light levels were the same in all mesocosms of 1 year (20052007, 2009) or varied only slightly (2008). Thus, the 2 mesocosms of 1 year primarily differed in grazing intensity as they were either subjected to different temperature treatments (2005-2008) or contained different initial copepod densities (2009). Thus, the divergence of community biomass among treatments in the first half of the experiments was probably due to differences in grazing intensity. This assumption is supported by the lack of divergence in $\mathrm{P} / \mathrm{B}$ in the first of the experiments and a very similar $\mathrm{D}$ of $\mathrm{P} / \mathrm{B}$ among all mesocosms of 1 year to that of the replicates. Grazing presumably promoted divergence of community biomass among the mesocosms more strongly than divergence of $\mathrm{P} / \mathrm{B}$. During and after the phytoplankton bloom, the mesocosms converged, indicating a stronger role of nutrient limitation in phytoplankton dynamics, which was similar among all mesocosms within 1 year. At the species level, $D$ of all mesocosms of 1 year was similar to that of the replicates. This indicates that individual species were probably similarly affected by the initial phytoplankton species composition (which was similar in all mesocosms in 1 year) than by forcing, which differed among the treatments. However, this pattern was also partly due to the methodology used here (see relevant section of Results).

In contrast to our second hypothesis, predictability at the species, group and community level was similar. $D$ of the replicates was around two for most hierarchical levels (Fig. 3). This value means an amplification of initial differences in biomass merely by a factor of two. This shows that even the most divergent replicates remained fairly similar. The similarity indicates that the spring dynamics of phytoplankton are predictable if the abiotic and biotic forcing factors are known. This agrees with the relatively high goodness of fit between data and models under strong abiotic forcing (e.g. Peeters et al., 2007; Tirok \& Gaedke, 2007). Only the taxonomic-functional group 


\section{B. Bauer et al.}

picophytoplankton had a significantly higher D than the other hierarchical levels (Fig. 3a). This was because of their typically very low $D$ values on the first three dates. This means that the initial abundances of the picophytoplankton in the replicates were more similar to each other than those of the total phytoplankton or the functional groups, which tended to differ more between the two replicates. This was either the consequence of their more even distribution in the water column or of the counting method, which was different from that of the larger algae (flow cytometry instead of inverted microscopy, see Methods).

There was no substantial and monotonous increase in $V_{t}$ either at the group (Fig. 2b) or at the species level, which would be expected, for example, in the case of systems with intrinsically chaotic dynamics (Hastings \& Powell, 1991). Although sometimes large $V_{t}$ values arose, especially at the species level, this was counterbalanced by 'reset' periods, where the replicates converged (sensu Grover \& Lawton, 1994). This finding is in contrast to the results of Beninca et al. (2008) who suggested that the maximum time-frame for species-level predictions is 1530 days. The experiments analysed in their study were run without directional forcing; thus, biotic interactions had a larger role than in our system, which might explain the lower predictability observed in their study. The implication of this pattern for modellers is that, from the viewpoint of predictability, aggregation of smaller units into larger groups is neither discouraged nor encouraged.

In accordance with our third hypothesis, convergence occurred at high community biomass (Fig. 4) presumably close to the carrying capacity (indicated by nutrient depletion, data not shown). The two replicates had similar nutrient concentrations, and they were run under the same light regimes. Thus, negative density dependence caused by nutrient depletion and, to a minor extent, selfshading was a mechanism that acted in both replicates when they reached high biomasses. If one of the replicates was approaching a high biomass faster than the other one, nutrient depletion slowed it down. This caused convergence of the mesocosms despite their potential differences in initial species composition. In nature, pronounced blooms and winter might serve as a general reset in terms of total biomass, but less for species composition (Dakos et al., 2009), and even less for organisms forming resting eggs and cysts. Another mechanism of community regulation is the numerical response of grazers. As a result of the short generation times of protozoans, they are especially likely to quickly track changes in phytoplankton biomass. Predator effects have been shown to be able to overrule the role of other interspecific interactions and historical effects (Morin, 1984). On the other hand, the occasionally large values of $V_{t}$ over short time scales observed in our study indicated the presence of positive feedbacks, which caused a runaway of biomass in one of the replicates. This warns against using distinct time points of transients for generalisations about the analysis of community dynamics and calls for longer community observations.

Supporting hypothesis four, the predictability of the $\mathrm{P} / \mathrm{B}$ ratio was similar to that of total community biomass (Fig. 3a). This indicates that mechanisms buffering as well as amplifying initial small differences were present, which prevented a lasting convergence or divergence.

Our study opens a new perspective on spring phytoplankton development; with the use of divergence and difference indices, we gained insight into the relevant factors affecting the predictability of phytoplankton biomass at different hierarchical levels. This method could be applied over a range of systems and trophic levels, to enable more quantitative insights into the predictability of communities and the expected reliability of forecast models.

\section{Acknowledgments}

The authors thank Stefanie Branscheid for help in organising the data and doing some calculations, Matthijs Vos, Lisette N. de Semerpont Domis and two anonymous referees for stimulating comments on a previous version of the MS, Caolan Kovach-Orr for the improvement of the writing style, and all the people participating in the mesocosm experiments. B. Bauer is funded by the Deutsche Forschungsgemeinsschaft (DFG) within the priority programme 1162 'The impact of climate variability in aquatic ecosystems' (AQUASHIFT).

\section{References}

Beninca E., Huisman J., Heerkloss R., Johnk K.D., Branco P., van Nes E.H. et al. (2008) Chaos in a long-term experiment with a plankton community. Nature, 451, 822-827.

Berlow E.L. (1997) From canalization to eontingeney: hister ical effects in a sucessional rocky intentidal community. Ecological Monographs; 67, 435-460.

Breithaupt P. (2009) The Impact of Climate Change on Phytoplankton - Bacterioplankton Interactions. PhD thesis. University of Kiel, Kiel.

Dakos V., Beninca E., van Nes E.H., Philippart C.J.M., Scheffer M. \& Huisman J. (2009) Interannual variability in species composition explained as seasonally entrained chaos. Proceedings of the Royal Society B-Biological Sciences, 276, 2871-2880. 
Grover J.P. \& Lawton J.H. (1994) Experimental studies on community convergence and alternative stable states Comments. Journal of Animal Ecology, 63, 484-487.

Hastings A. \& Powell T. (1991) Chaos in a three-species food chain. Ecology, 72, 896-903.

Holt R.D. (1977) Predation, apparent competition, and structure of prey communities. Theoretical Population Biology, 12, 197-229.

Lewandowska A. (2011) Effects of Warming on the Phytoplankton Succession and Trophic Interactions. PhD thesis. University of Kiel, Kiel.

Lewandowska A. \& Sommer U. (2010) Climate change and the spring bloom: a mesocosm study on the influence of light and temperature on phytoplankton and mesozooplankton. Marine Ecology-Progress Series, 405, 101-111.

Luo Y., Ogle K., Tucker C., Fei S., Gao C., LaDeau S. et al. (2011) Ecological forecasting and data assimilation in a data-rich era. Ecological Applications, 21, 1429-1442.

Menden-Deuer S. \& Lessard E.J. (2000) Carbon to volume relationships for dinoflagellates, diatoms, and other protist plankton. Limnology and Oceanography, 45, 569-579.

Morin P.J. (1984) Odonate guild composition - experiments with colonization history and fish predation. Ecology, 65, 1866-1873.

Morin P.J. (1995) Functional redundancy, nonadditive interactions, and supply-side dynamics in experimental pond communities. Ecology, 76, 133-149.

Peeters F., Straile D., Lorke A. \& Ollinger D. (2007) Turbulent mixing and phytoplankton spring bloom development in a deep lake. Limnology and Oceanography, 52, 286-298.

Rahel F.J. (1990) The hierarchical nature of community persistence - a problem of scale. American Naturalist, 136, 328-344.
Sommer U., Aberle N., Engel A., Hansen T., Lengfellner K., Sandow M. et al. (2007) An indoor mesocosm system to study the effect of climate change on the late winter and spring succession of Baltic Sea phyto- and zooplankton. Oecologia, 150, 655-667.

Sommer U., Gliwicz Z.M., Lampert W. \& Duncan A. (1986) The PEG-Model of seasonal succession of planktonic events in fresh waters. Archiv für Hydrobiologie, 106, 433-471.

Sommer U. \& Lengfellner K. (2008) Climate change and the timing, magnitude, and composition of the phytoplankton spring bloom. Global Change Biology, 14, 1199-1208.

Sommer U. \& Lewandowska A. (2011) Climate change and the phytoplankton spring bloom: warming and overwintering zooplankton have similar effects on phytoplankton. Global Change Biology, 17, 154-162.

Sommer U. \& Sommer F. (2006) Cladocerans versus copepods: the cause of contrasting top-down controls on freshwater and marine phytoplankton. Oecologia, 147, 183-194.

Tilman D. (1990) Constraints and tradeoffs - toward a predictive theory of competition and succession. Oikos, 58, 3-15.

Tirok K. \& Gaedke U. (2007) The effects of irradiance, vertical mixing and temperature on spring phytoplankton dynamics under climate change: long-term observations and model analysis. Oecologia, 150, 625-642.

Tukey J.W. (1951) Quick and dirty methods in statistics, part II. Simple analysis for standard designs. In: Proceedings of 5th American Convention; American Society for Quality Control. pp. 189-197.

(Manuscript accepted 28 February 2012) 